\title{
The Dependence of Ancient Greek Geometry and Metaphysics on Craft-Culture
}

by

\author{
Philip Thibodeau
}

Brooklyn College

pthibodeau@brooklyn.cuny.edu 


\begin{abstract}
A discussion of Robert Hahn's The Metaphysics of the Pythagorean Theorem: Thales, Pythagoras, Engineering, Diagrams, and the Construction of the Cosmos out of Right Triangles.
\end{abstract}

\begin{abstract}
About the Author
Philip ThiBodeAu is a professor in the Classics Department at Brooklyn College, City University of New York. He studies early Greek scientists and the social and multicultural contexts in which their work evolved. His most recent work is a monograph, The Chronology of the Early Greek Natural Philosophers, available for free download at https://www.cosmographia.net. He is currently working on a study of the chronology of the poems of Homer and Hesiod. His published works also include studies of ancient Greek and Roman agriculture, ancient theories of vision, Horace's Odes, and Vergil's Georgics.
\end{abstract}




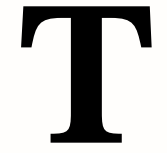

he study of ancient philosophy is never more fascinating-or more frustrating - than when it deals with thinkers who left behind nothing in writing. This category includes three of the most famous names in Greek philosophy: Thales, Pythagoras, and Socrates. Without a fixed text or even fragments of such a text to work with, any scholarly attempt to interpret their doctrines-to explicate their details, reconstruct how they arose, and study how they were applied-will always be shadowed by fundamental doubts about their actual nature. At least in the case of Socrates, we have a great deal of indirect evidence at our disposal in the massive Platonic corpus, together with other literary works, like Xenophon's memoirs and Aristophanes' Clouds, which can serve as a check on Plato's testimony. But when it comes to Thales and Pythagoras, we are much less fortunate; for each thinker, fewer than a dozen pieces of testimony survive that date to within two human lifespans of their deaths, most no more than a few sentences in length. Since what we have is so limited, any new insight into the nature of their thought or teachings, however slight it may be, is potentially of great interest.

In his new study, The Metaphysics of the Pythagorean Theorem: Thales, Pythagoras, Engineering, Diagrams, and the Construction of the Cosmos out of Right Triangles, Robert Hahn [2018] proposes that such insight can be had if we are willing to explore the implications of the geometrical discoveries made by Thales and Pythagoras. His specific hypothesis is that the two men not only laid the foundations for geometry as a formal, deductive science by revising the mensuration-techniques of Greek and Egyptian craftsmen, they also endowed it with a new, metaphysical meaning. Hahn is here reprising and extending an approach that he developed in previous studies of Anaximander, which aim to show how contemporary craft-practices provided early Greek philosophers with mental models and other habits of reasoning that, once directed at the natural world, helped give rise to natural philosophy. His first book, Anaximander and the Architects [Hahn 2001], centered on the proposition that the construction of monumental column-drums by such contemporary architects as Theodorus and Rhoecus prompted Anaximander to think in analogous terms about the form and proportions of 
the cosmos; hence, the cosmologist's striking assertion that the Earth "resembles a stone column" [Hippolytus, Ref. 1.6.3] and his further claim that the Earth is one third as deep as it is wide, its proportions thus strikingly similar to those of a lone column-drum. Hahn's "thick description" of architectural practice during Anaximander's lifetime-construction-plans, models, building techniques, Egyptian influences-made these little fragments come alive, and gave weight to his plea that architecture be granted as much attention as politics or literacy when questions about the origins of Greek philosophy are raised.

In a follow-up study, Archaeology and the Origins of Philosophy [Hahn 2010], Hahn pursued this line of inquiry further, arguing that Anaximander's famous Sun and Moon "wheels"- two massive, mist-wrapped wheels of fire which define the orbits of the two bodies-were influenced conceptually by the massive wooden wheels used to transport building stone in Ionia. He also showed how archaic smelting technology informed Anaximander's comparison of the visible faces of the Sun and Moon to a furnace's vent-pipe. The book concludes with a theoretical justification for this focus on archaeology, with texts from Dewey, James, and Putnam brought in to support the claim that knowledge is always embedded in material realities and, thus, that close study of material culture should be an essential part of any reconstruction of ancient philosophy. To this roster of modern authorities, Hahn could also have added Aristotle, who in his account of the development of

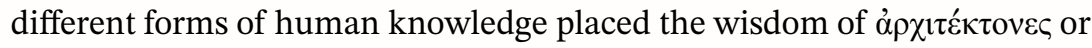
master builders just one step below that of philosophers proper [Meta. 1, 981a24-b24].

A reader of Hahn's first two books-both of them lucidly written and richly illustrated-is apt to come away persuaded that Anaximander engaged in serious reflection on contemporary craft-culture, and that many compelling and original features of his cosmology owe something to that reflection. In describing the philosophical significance of this material, however, the books sometimes go too far. The position which Hahn argues for is not just that a confrontation between archaeological and doxographical evidence can be fruitful, but that architectural thinking lay at the core of Anaximander's vision of the cosmos. Now, the surviving doxography for Anaximander gives pride of place to the doctrine of the "A $\pi \varepsilon i \rho o v$, an originary being from which the elements emerge and to which they eventually return. In his treatise, Anaximander further sought to account for the creation of the existing world, the cycling through of various kó $\mu$ or or world-orders, the formation and eventual disappearance of the ocean, the creation of the first human 
beings out of fish-like creatures, and the physical causes of wind, rain, and lightning. These important doctrines are, unfortunately, not illuminated in any way by an understanding of architectural practice. Only those facets of his cosmology that involve structure, measure, or form benefit in this way. So, unless natural philosophy is seen as something primarily concerned with the study of cosmic structures, it is going too far to treat craft-based thinking as instrumental in the formation of his core teachings. Study of the impressive remains of Ionian temples or archaic technology is still very valuable, but chiefly for the way in which it can make our reconstructions more grounded, meaningful, and accurate.

In his new book, Hahn again aims high, aspiring to show not just that Greek geometry as practiced by Thales and Pythagoras developed from Egyptian techniques of mensuration, but that they endowed it with metaphysical significance. Before reviewing the particular arguments for this, I would note that nearly half of the pages in this book are given over to clear, step-bystep explications of numerous Euclidean propositions - the "Pythagorean theorem" [Elem. 1.47] together with its "enlargement" [Elem.6.31], and several other theorems from books 1, 2, 6, and 10-all illustrated with large, attractive, color diagrams. These expositions are meant to show how much of Euclidean geometry centers on problems involving the application of areas, the scaling up and down of similar shapes, and the theory of proportions. Hahn's commentaries on these theorems are sensible and make for rewarding reading. In some ways, this material constitutes one book-an introduction to the fundamental principles of Euclidean geometry-that has been folded into a second one exploring the origins of Greek geometry and its metaphysical implications. The first of these "books" is cautious and conservative, while the second is much bolder and full of imaginative leaps, not all of which the reader may feel safe taking.

Eudemus of Rhodes, in his authoritative History of Geometry [Proclus, In Euc.: Friedlein 1873, 65.7], reported that Thales was the first to introduce Egyptian geometrical science to Greece. According to Hahn, Thales learned three things during his Egyptian sojourn:

(1) formulas and recipes for calculating the area of rectangles and triangles, volumes, and the height of a pyramid...(2) from the land surveyors, he came to imagine space as flat, filled by rectilinear figures, all of which were reducible ultimately to triangles to determine their area; (3) watching the tomb painters and sculptors, he recognized geometrical similarity: the cosmos could be imagined as flat surfaces and volumes articulated by squares, and each thing can be imagined as a scaled-up smaller version. [12] 
In his lengthy introduction, Hahn walks us through the technique of Egyptian land-surveying, a few representative problems from the Rhind Mathematical Papyrus, and the wall-painters' practice of laying out grids to define the proportions of figures. A good general case is made here for the Greek inheritance of these techniques from Egypt. Yet, it must be said that none of our sources expressly credits Thales with the introduction of rules for calculating areas or dissecting shapes; all they suggest is that Thales understood how the power of geometrical similarity could be used to solve problems in mensuration. Thales' method for determining the distance of ships at sea seems to have rested on a construction involving similar triangles [108-113]. He also reportedly used similar triangles to measure the height of the Great Pyramid at Giza, treating the vertical axis of the pyramid and its shadow as sides of an isosceles triangle similar in proportion to a smaller triangle formed by a gnomon and its shadow.

In the course of what must have been a fascinating study-abroad visit to Egypt, Hahn had a group of students replicate this measurement [97-107]. While their efforts proved successful, they discovered that there are only a handful of days during the year when the Sun reaches the requisite altitude of $45^{\circ}$ in the sky while standing due south, east, or west; on other days, the shadow is either shorter than the base of the pyramid or not aligned with its major axes, situations which render the measurement impossible. Hahn is to be applauded for documenting the attempt and the difficulties that he encountered. To my mind, however, the difficulties feed a suspicion that the story is apocryphal — the earliest source for it, Hieronymus of Rhodes, was a collector of miscellanea from the third century BC.

Nevertheless, the account of Thales' measurement of distance at sea goes back to Eudemus, our most reliable authority for early Greek geometry, and we have no good reason to reject it. Hahn's argument that Thales discovered the principle of geometrical similarity by studying the use of grids in art, either in Egypt or, perhaps, in Ionia, where sculptors in his day were already employing it [Diodorus Siculus, Bib. hist. 1.98.5-9], is quite plausible.

In his introduction, Hahn also draws on archaeological research to argue that Greek geometers were using lettered diagrams as early as the middle of the sixth century $\mathrm{BC}$ [35-41]. Here he is mounting an explicit challenge to Reviel Netz' claim [2004] that such diagrams did not come into use until about a century later. For evidence, Hahn cites the famous tunnel dug through Mt. Castro on Samos by the Megarian engineer Eupalinus during the reign of Polycrates in $c a 530 \mathrm{BC}$. On its walls was painted a series of Greek letters, spaced every 20.6 meters, which served to mark the length of the tunnel. 
Near its midpoint, the tunnel makes a curious triangular zigzag. Kienast's explanation for this feature [2005], which Hahn follows, is that ancient diggers had encountered an area of soft stone and, in order to avoid it, deviated westward, then bent back towards the east before resuming their original course. The detour resulted in the tunnel being an extra 17.6 meters long. Someone who thought this fact worth recording marked off an interval of 17.6 meters on one wall, accompanied by the inscription «ПАРА $\triangle \mathrm{E} \Gamma \mathrm{AA}$ » Hahn argues, to my mind persuasively, that the deliberate way in which this detour was marked implies that Eupalinus was working with a master sketch or diagram that featured the same letters as those painted on the wall. That said, the fact that Eupalinus apparently made use of a line-diagram with letters on it does not constitute a counterexample to Netz' claim. Lettered diagrams in geometrical texts differ considerably from this putative drawing in their pragmatic function. As Netz has explained in great detail [1999], such diagrams were designed to complement and complete the verbal statement of a proof for a given proposition; their letters serve as indicial marks, designating the particular points (and, by extension, lines and angles) that are named in the verbal account. By contrast, the purpose of Eupalinus' drawing was, one presumes, to provide an objective visual record of the progress of the tunneling. Technically, the marks should be regarded not as letters or indices but as numerals, counts of the 20.6-meter measures in the tunnel; the marks are in fact considered the earliest known deployment of alphabetical numerals [Kienast 1995, 148-160]. So Eupalinus' tunnel does not provide clear evidence that diagram-based geometry was already being practiced in the time of Thales or Pythagoras. Hahn would have been on firmer ground had he argued that the classic lettered diagrams of Greek geometry evolved from engineering drawings like Eupalinus'; confirmation for such a claim might even be forthcoming some day, if excavations should turn up more examples of lettered plans dating to the early fifth century BC. The other claims that Hahn puts forward in this study revolve around geometrical metaphysics and the broad thesis that Thales and Pythagoras both understood the structures of the world to be composed of triangles-in particular, right triangles. The anchor for this line of argument is the famous passage in the Timaeus $[53 \mathrm{c}-55 \mathrm{c}]$ where Plato asserts that the material continuum of space constitutes a tiling of microscopic triangles, which, when clustered, form the polygonal faces of five regular solids, each complete solid representing an elemental particle (save for the dodecahedron, which is somehow linked to the cosmos as a whole). It is natural to wonder whether this theory of geometrical atomism was wholly Plato's brainchild 
or whether it might represent an elaboration of a doctrine held by prior thinkers. Pythagorean precedents have long been suspected, given that the Pythagorean Ecphantus of Syracuse ( $c a$ 400 BC) expounded a teleological atomism, and that Pythagoras-or perhaps his student Hippasus-reportedly discovered the regular solids. Hahn takes this Pythagorean background as given and also regards as true Proclus' claim that the ultimate goal of Euclid's Elements was to teach the reader how to construct the five regular solids [198-201]. By his reading, much of the early tradition of Greek geometry was in the service of this larger project. He then interprets Pythagoras' discovery of the regular solids with the help of the passage in the Timaeus, arguing that the discovery arose from an attempt to explain how the world could be composed out of right triangles [198-212]. Thales is brought into this picture as the source for the insight that all rectilinear shapes can be reduced to collections of triangles [29-32 ff.]. Finally, it is argued that Thales and Pythagoras read metaphysical significance into the fact that geometrical shapes can be scaled up and down, and areas of constant size transformed from one shape into another [82-89 ff.].

Attributing the All-is-Triangles thesis to Pythagoras does motivate his apparent interest in the regular solids, which is otherwise rather hard to account for. But the shortcomings of such a reconstruction are rather severe. Even if we prefer Leonid Zhmud's Pythagoras [2012, 270-283] to Walter Burkert's [1972, 447-465] and see the Samian as making significant contributions to geometry, there is no direct evidence linking him to the triangle-hypothesis or to its metaphysical interpretation. Over a century ago, the influential historian of science Paul Tannery put forward a proposal similar to Hahn's, positing a Pythagorean geometrical atomism that was the target of criticisms made by Zeno [1887, 258-261]. Tannery's hypothesis was further developed by Cornford and others, but no longer has defenders. The reasons for its abandonment are sound. As for Thales, no source ascribes to him the doctrines with which he is credited here. For want of direct testimony, Hahn argues that Thales must have drawn many geometrical diagrams"to begin to understand Thales and his geometrical speculations, we have to understand that he must have made countless diagrams" [96] - in the course of which these insights would have become all but inevitable. But, to my mind, his conclusion that Thales must have known an early version of the Pythagorean theorem [116-133] highlights the risks rather than the advantages of such a way of proceeding. The assertion is also made that Thales was inspired to develop a geometrical metaphysics in order to quiet critics who were sceptical of his assertion that water was the fundamental 
substance [29]. On this reading, Thales' triangle-hypothesis was designed to make his theory of water more palatable; but how it would have done so is left wholly unclear. Much more plausible is Hahn's running argument that the earliest Greek geometers (whom, following Netz, I would date to the fifth century, not the sixth) were deeply fascinated by the principles of geometrical equality, similarity, proportion, and magnitude. A book less focused on metaphysics might have been able to draw more interesting connections between craft-practice and the theoretical study of these elementary concepts.

This book's more audacious claims run far beyond the surviving evidence, and the effort to tease them out as implications is not carried off successfully. Nevertheless, its discussions of Euclid, the quality of its layout and presentation, and the investigations of archaic material culture make the book worthwhile. Hahn's deep dives into the $\tau \dot{\varepsilon} \chi v \eta$-tradition represent a substantial contribution to scholarship; few researchers have traced the links between technology and philosophy in pre-Aristotelian thought with such care. Our understanding of the world in which Thales and Anaximander worked is sharpened by Hahn's discussion of contemporary techniques of design, even if his attempt to bring Pythagoras into clearer focus falls short. To conclude, I would observe that many early philosophers besides Thales and Anaximander found the crafts "good to think with". Is it too much to hope for a future monograph with a title along the lines of Empedocles' Lantern, Heraclitus' Game-Board, and Plato's Fish-Trap? There are not many scholars who would be in a better position to write it.

\section{BIBLIOGRAPHY}

Burkert, W. 1972. Lore and Science in Ancient Pythagoreanism. E. L. Minar Jr. trans. Cambridge, MA.

Friedlein, G. 1873. Procli Diadochi primum Euclidis Elementorum librum commentarii. Leipzig. Repr. Hildesheim, 1967

Hahn, R. 2001. Anaximander and the Architects: The Contributions of Egyptian and Greek Architectural Technologies on the Origins of Greek Philosophy. Albany, NY. 2010. Archaeology and the Origins of Philosophy. Albany, NY. 
Hahn, R. 2018. The Metaphysics of the Pythagorean Theorem: Thales, Pythagoras, Engineering, Diagrams, and the Construction of the Cosmos out of Right Triangles. Albany, NY.

Kienast, H. J. 1995. Die Wasserleitung des Eupalinos auf Samos. Bonn. 2005. The Aqueduct of Eupalinos of Samos. Athens.

Netz, R. 2004. "Eudemus of Rhodes, Hippocrates of Chios and the Earliest Form of a Greek Mathematical Text”. Centaurus 46: 243-286.

1999. The Shaping of Deduction in Greek Mathematics: A Study in Cognitive History. Cambridge, UK.

Tannery, P. 1887. Pour l'histoire de la science Hellène. Paris.

Zhmud, L. 2012. Pythagoras and the Early Pythagoreans. K. Windle and J. Ireland trans. Oxford. 